\title{
MODOS DE NEGRA E MODOS DE BRANCA: O RETRATO BAIANA E A IMAGEM DA MULHER NEGRA NA ARTE DO SÉCULO XIX
}

Renata Bittencourt

\section{Resumo}

Ensaio sobre a pintura conhecida como "Baiana" do acervo do Museu Paulista da Universidade de São Paulo, buscando estabelecer relações com os costumes culturais de seu contexto de origem, bem como a iconografia do século XIX, com foco na representação pautada por questões de gênero e etnicidade.

\begin{abstract}
This study is an investigation about the painting known as "Baiana"that belongs to the Museu Paulista/USP collection. It relates the painting to the cultural habits and values of its time, as well as with the iconography of the 19th century. Gender and ethnicity are central to the research.
\end{abstract}

Esta investigação tem como objeto a obra conhecida como "Baiana" (fig. 1) do acervo do Museu Paulista. A pintura é um caso raro de retrato de mulher negra na pintura no século XIX. O objetivo foi buscar conhecer esta pintura que se apresenta de maneira singular na retratística do período, surgindo como imagem reveladora de seu contexto histórico e cultural, bem como de relevantes questões relacionadas a gênero e etnicidade. A pesquisa levantou hipóteses sobre a posição social da mulher negra retratada na pintura, analisando elementos visíveis em sua composição como indumentária e joalheria. Um dos focos centrais desta investigação está relacionado à estética híbrida apresentada na obra, que apresenta elementos de distinção social habituais à elite brasileira e outros relacionados à herança africana e afrobrasileira. Foram analisadas questões relacionadas ao gênero do retrato e suas dimensões simbólicas vinculadas à afirmação de poder na sociedade escravocrata do Brasil do século XIX.

São poucos os retratos individuais de negros na iconografia do século XIX, e mais raros os retratos de mulheres negras. Os exemplos são mais numerosos na produção de artistas viajantes e também, mais tardiamente, nos registros fotográficos produzidos nos estúdios de diversas partes do país. O retrato estudado pertence ao acervo do Museu Paulista da Universidade de São Paulo. Não há na documentação do museu informações acerca da mulher retratada e a denominação adotada como título da obra, "Baiana", se deve à origem dos colares, conforme veremos mais adiante. Não há assinaturas sobre a tela ou anotações em seu verso. Também não foi encontrada qualquer documentação disponível no museu. Não foi possível localizar através dos responsáveis pelo acervo qualquer registro de sua procedência ou data de incorporação à coleção. Apesar de não haver dados suficientes para uma atribuição de autoria, é possível destacar a qualidade da fatura observada na pintura. A obra participou de algumas exposições recentes. Foi incorporada, à exposição O Universo Mágico do Barroco Brasileiro realizada na FIESP/Sesi em 1998, onde apareceu datada como uma pintura do século XVIII, o que pode ser questionado em função da indumentária e de suas semelhanças estilísticas com obras do oitocentos. Em 2000 fez parte da Mostra do Redescobrimento no núcleo Negro de Corpo e Alma que ocupou o Pavilhão Manoel da Nóbrega. Esteve de volta ao mesmo local em 2002 na 
exposição Memórias de negro: negras memórias. Todas as exposições mencionadas tiveram Emanoel Araújo ${ }^{1}$ como curador.

Para melhor compreender a pintura em questão, vale a pena aludir aos padrões de representação feminina criados ao longo da história da arte. Podemos identificar duas tradições marcantes: uma versão sensualizada que retraça a representação de Vênus, em renovados elogios ao corpo feminino e outra vertente, complementar, que valoriza a virtude feminina em que a mulher é vista como a jóia do lar e de seu marido. São exemplos as obras "A Fornarina" (1520, óleo sobre madeira, 85 × 60 cm, Galleria Nazionale d'Arte Antica, Roma) e "Dona Velata" (1520, óleo sobre madeira, 85 x 64 cm, Palazzo Pitti, Florença) de Rafael, grande nome da era áurea do retrato, e Ingres, figura central da representação feminina no século XIX. Este transitou entre esta herança dupla tendo de um lado suas figuras de banhistas e odaliscas, e de outro, retratos de senhoras da elite ricamente vestidas e ornamentadas. Podem ser citadas as pinturas "Retrato de Madame Sennones" (1814, óleo sobre tela, 106 x $84 \mathrm{~cm}$, Musée des Beaux-Arts, Nantes) e "A Grande Odalisca" (1814, óleo sobre tela, 910 x 162 cm, Louvre, Paris).

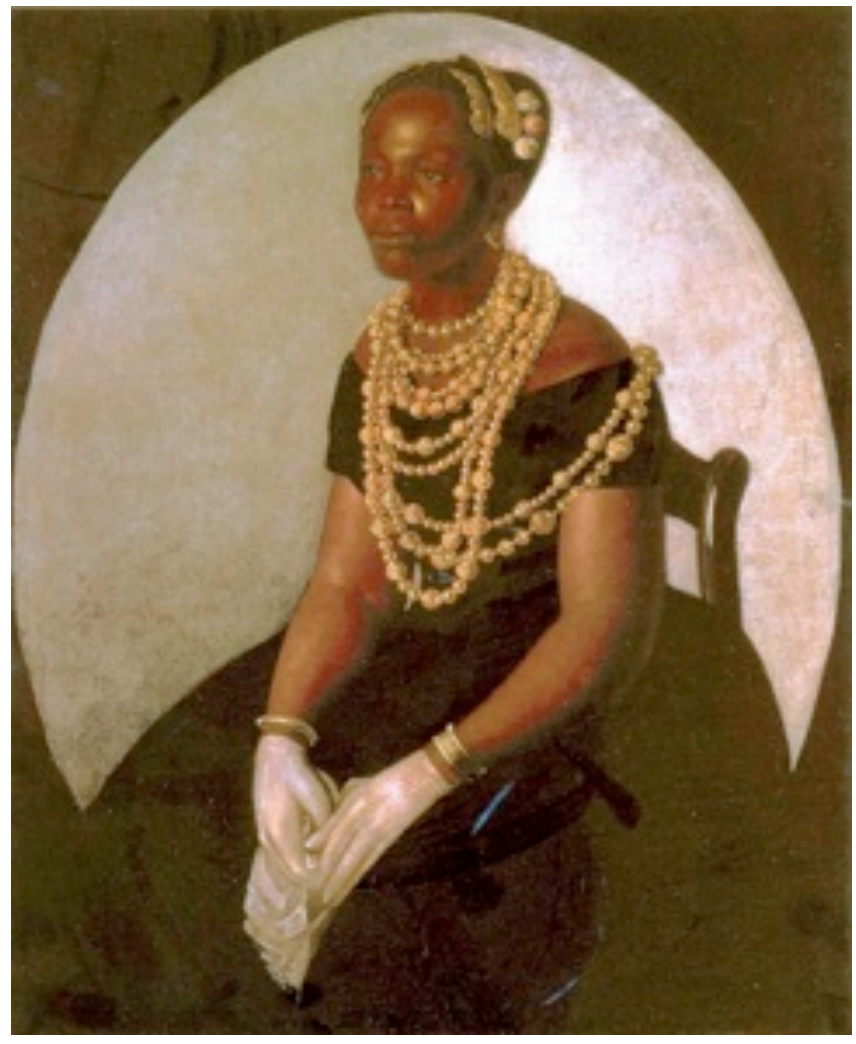

[Fig. 1] Baiana, Anônimo, s. d., Óleo sobre tela, 95,5 x 76,5 cm, Museu Paulista/USP, São Paulo.

\footnotetext{
1 Araújo, artista plástico e ex-diretor da Pinacoteca do estado de São Paulo, tem tido um importante papel na difusão de obras relacionadas à iconografia e ao imaginário negro, bem como à produção de artistas afrobrasileiros. Realizou diversas exposições como Herdeiros da Noite e Arte e Religiosidade no Brasil, na Pinacoteca, bem como em outras instituições brasileiras. Araújo foi secretário municipal de cultura de São Paulo em 2005 e diretor do Museu Afro - Brasil.
} 
No Brasil do século XIX, é possível reconhecer a presença das duas linhagens de representação que observamos em Rafael e Ingres. O retrato "Baiana" parece se relacionar mais diretamente com àquela que valoriza a mulher em sua dócil domesticidade, onde os símbolos materiais de distinção nos informam sobre sua posição e papéis sociais. A pintura "Baiana" se encontra alinhada com a compostura da mulher coberta com véu, e o apreço pela ornamentação de "Madame Sennones". Mas é a representação feminina que atenta para o corpo em imagens de menor individuação, que parece ser uma matriz constante na produção de imagens de mulheres negras dos artistas do oitocentos.

As representações feitas por viajantes do século XIX tentam circunscrever a admiração da mulher negra à dimensão material de seu corpo, visto como exemplar de um coletivo definido pela cor da pele. No entanto as imagens que nos chegam oscilam entre a indignidade da objetificação e a poética homenagem à beleza negra.

Exemplos da importância dada ao corpo feminino na produção dos viajantes são as belíssimas aquarelas de Hercule Florence. Na aquarela, "Negra Rebolo" (1828, nanquim e aquarela, 27 x 21, $5 \mathrm{~cm}$, Arquivo da Academia de Ciências de São Petersburgo, São Petersburgo), o artista deposita diferentes tons de marrom sobre o papel para criar o modelado da figura, criando zonas de claro e escuro sobre o rosto de expressão triste. O contraste da roupa branca contra a pele negra chama a atenção, assim como as pequenas contas em volta do pescoço. O cabelo crespo forma um padrão irregular sobre a face. A imagem da mulher rebolo traz um aspecto em particular. Seu seio não está exposto em função do deslocamento de tecidos ou em função de blusas que lhe caem dos ombros. Aqui a modelo se despe como que atendendo a um pedido do artista.

Apesar de defendermos um parentesco entre imagens como esta e a tradição do nu, é importante aqui apontar a diferença entre este e o estado de nudez. Em inglês os termos naked e nude possuem significados diferentes. Segundo Clark (1956, p.3) estar nu (naked) significa estar privado de roupas, o que implica em costumeiro embaraço e vulnerabilidade, enquanto termo o nu quando ligado à arte (nude), não implica em desconforto. Ao contrário, projeta a imagem de um corpo confiante e em equilíbrio.

Enquanto a "Grande Odalisca" aspira pela pureza da forma, o corpo das mulheres negras observadas pelos viajantes parecem imbuídas de uma dimensão carnal acentuada. Por vezes a exposição de seus corpos é expressão de hábitos trazidos da África. Em outros o ato de despir as modelos (naked bodies) já afasta as imagens do nu idealizado. De acordo com Parkes (1998, p.223):

As imagens reproduzem no âmbito ideológico da arte as relações de poder entre homens e mulheres. A mulher está presente enquanto imagem, mas com as conotações específicas de corpo e natureza, ou seja, passiva, disponível, impotente. O homem está ausente da imagem, mas o que esta significa é a sua fala, sua opinião e sua posição de domínio.

Esta passagem, originalmente relacionada à tela "O Nascimento de Vênus" de Cabanel, nos ajuda a refletir sobre a dimensão de poder entre artistas e retratados. Embora o foco dos autores em seu estudo sobre a objetificação, seja a diferença de gênero, podemos estender este sentido de alteridade às diferenças existentes entre negros e brancos, escravos e libertos, e as respectivas relações de poder estabelecidas entre as partes. 
Se comparado ao exemplo anterior, a obra "Negra Cabinda" (Hercule Florence, 1828, nanquim e aquarela, 29 × $22 \mathrm{~cm}$, Arquivo da Academia de Ciências de São Petersburgo, São Petersburgo) oferece um registro de menor vulnerabilidade. O olhar assertivo acrescenta dignidade à exposição do intrincado padrão de suas cicatrizes étnicas e de seu colar de contas africanas. A jovem mulher parece devolver o olhar observador e curioso de Florence. Montes escreve (MONTES, 2000, p.65) sobre o corpo dos escravos e o modo como suas marcas corporais constroem sua identidade:

[no corpo] se lêem escarificações, penteados e adornos, marcas africanas de humanidade e pertencimento, como sinais de barbárie, enquanto marcas de propriedade, gravadas a ferro sobre o corpo do escravo, e as roupas que se vê obrigado a cobrir-se, são assinaladas como marcas de civilização. Pelo corpo se compreende a condição social de cada um, sua posição e status - pelas roupas que veste, pelo calçado, pelos pés descalços, marca inconfundível da escravidão.

Assim como as jóias e ornamentos que vemos nos retratos herdeiros da tradição de representação casta que vimos anteriormente, as cicatrizes sobre a pele convidam o olhar a percorrer o corpo detidamente. A frontalidade, ao contrário do pudor parcial exibido na torsão da odalisca que parece querer ocultar parte de si, disponibiliza o corpo à observação curiosa, propositiva ao desejo do observador. Nos diz Valéry (PARKES, 1998, 223):

Quando Ticiano apresenta uma Vênus puramente carnal, suavemente extendida em púrpura e em toda a plenitude de sua perfeição enquanto deusa e tema para a tinta, fica óbvio que para ele pintar quer dizer acariciar, uma conjunção de duas sensações voluptuosas em um único ato supremo no qual o autodomínio de seu veículo foram identificados com a posse dominadora da própria beleza, em todos os seus sentidos.

A posse momentânea e virtual do artista sobre seu modelo, e o desejo de toque sublimado na superfície da pintura não eliminam, nos exemplos de Florence, a função de sugestão da imagem no que se refere à cultura que ela quer exemplificar. Mais do que traduzir na superfície pictórica o ato sublimado do toque, estas imagens remetem às possibilidades reais de contato visual e até sexual com estas mulheres. As imagens levaram à Europa a visão destes corpos escravos e submissos. Disponíveis aos olhos e passíveis de posse. As aquarelas de Florence foram criadas a partir de mulheres específicas e o artista não lança mão de artifícios para tornar a nudez aceitável aos padrões morais vigentes, como faz de modo recorrente a arte acadêmica. Neste caso, não se trata de arte destinada aos salões. Essas imagens se revestem de objetivos documentais. Também o fato de serem mulheres negras por si só já cria o distanciamento necessário para que os observadores sejam lenientes com a exposição de corpos que vemos. A alteridade exotizante da inexistente Odalisca é transposto para cenários mais reais, povoados de mulheres anônimas. É por estas operações que se inocenta, aparentemente, estes nus. O que parece se destacar em obras como estas, é o fato de expressarem uma percepção que mais do que generalizada, é legitimada socialmente. Estas imagens refletem concepções de prazer endossadas pelo seu momento histórico.

[...] a visão do corpo nu - real ou representado -, como a visão de tudo que possui conotação erótica, nunca é efetivada de um ponto de vista exterior: ocasiona um estado de participação, que pode aliar o estético ao erótico, sim, mas que jamais deixa de ser erótico (PESSANHA, 1992, P.50). 
O retrato "Baiana" está na contramão das perspectivas de representação de tipos e também da apresentação de corpos disponibilizados. Nega a dimensão erótica que se impõe às mulheres negras e recusa a identidade generalizante que ignora a individualidade. Sua dignidade não se estabelece pela idealização, mas transparece em suas características únicas e diferenciadas. Mesmo sua origem e relação com uma tradição africana ou afro-brasileira é informada por um elemento localizado fora de seu corpo. Não são cicatrizes, mas a profusão de colares que a conectam a uma estética negra. Não é uma evidência de local ou grupo de origem que a caracterizam, mas um elemento cultural crioulo, afro-brasileiro.

As imagens exotizantes se repetem na produção fotográfica de retratos. O pequeno formato $(6 \times 9,5 \mathrm{~cm})$ e o custo reduzido, tornaram a cartes-de-visite um modismo internacional na década de 1860, ajudando a disseminar a produção de retratos fotográficos. Utilizado como presente a parentes e amigos, apresentou produção constante até o final do século XIX. As marcas de diferenciação cultural africana ou afro-brasileira serão freqüentemente observadas nos retratos de escravos. Quando os negros são vistos como objeto das imagens, ao invés de sujeitos voluntários, é que encontramos os trajes de baiana e suas jóias, os instrumentos de trabalho e as marcas nos rostos (Nu de Jovem de Salvador, c. 1869, Albúmen, carte-de-visite, 9 × 5,6 $\mathrm{cm}$, Coleção Reiss-Museum Mannheimfigs; Moça de Salvador, Albúmen, carte-de-visite, 9 x 5,6 cm, Coleção Reiss-Museum Mannheim; Moça Cafuza, c. 1869, Albúmen, carte-de-visite, 9 x 5,6 cm, Coleção Institut für Länderkunde, Leipzig). Vemos nestas imagens de Henschel como também cabelo crespo e pele negra surgem em destaque como índices de identidade. Em outra chave surgem os retratos surgidos na esteira da popularização da fotografia. Neste contexto surgem as iniciativas de auto-representação de homens e mulheres negras livres e libertos, que buscavam na fotografia o espelhamento de sua condição emancipada, e seu desejo de inserção social. A necessidade de desvencilhamento da identidade de escravo estava ligada a estratégias de busca de status, mas também de sobrevivência. Nestes retratos surge o desejo de exibir uma prova material de existência no mundo por parte daqueles que conseguiram escapar da condição desumana de cativeiro (Retrato de Antonia, escrava alforriada, s.d., Firmino e Lins, Cartede-visite, Joaquim Nabuco, Recife). Mulheres forras com maior possibilidade de circulação e poder sobre seus próprios caminhos, procuravam inserir-se na sociedade para minimizar o estigma da escravidão e da cor da pele buscando a construção de uma identidade híbrida que acomodasse os valores da elite branca. Modos, hábitos e indumentária passavam a espelhar a cultura da elite escravocrata.

Com efeito a moda é um dos instrumentos mais poderosos de integração e desempenha uma função niveladora importante, ao permitir que o indivíduo se confunda com o grupo e desapareça num todo maior que lhe dá apoio e segurança. E como as modas vigentes são sempre as da classe dominante, os grupos mais próximos estão, a cada momento, identificando-se aos imediatamente superiores através da imitação da vestimenta (SOUZA, 1987, P. 135).

Os elementos de distinção social e cultural são aqui os elementos de grande peso no desenho da identidade da retratada na pintura "Baiana". Mesmo quando comparado aos retratos fotográficos, observamos diferenças notáveis. Podemos observar retratos que exibem retratados de modo a caracterizar tipos exemplares da cultura africana e afro-brasileira, ou indivíduos cuja indumentária reproduz os padrões da elite branca. Aqui o que se vê é uma sobreposição de elementos ocidentais (vestido, luvas, acessórios de cabelo, penteado, pose) e 
outros que denotam a origem africana, ou crioula, da personagem (cor da pele, colares de ouro).

Uma negra liberta certamente teria dificuldade em se inserir socialmente e estabelecer seu círculo de relacionamento se adotasse o visual das "negras novas". A visualidade associada a uma maior proximidade da África, devia ser evitada para garantir uma percepção social diferenciada. Concretamente isso se traduzia em costumes como: no uso de sapatos e sandálias, no corpo coberto, no abandono da tradição de marcas faciais, o uso de roupas e penteados ocidentalizados. Portar um novo vestuário, é importante dizer, também se constituía em exercício de uma nova condição, visível também para outros negros, e não apenas para a sociedade branca. Mas refletindo sobre as manifestações reconhecidas de preconceito observadas no Brasil do século XXI, cabe questionar em que medida estes sinais eram efetivos ao facilitar a inserção destas mulheres. Além disso, como observamos, as escravas também exibiam sinais semelhantes, com o propósito de promover seus senhores. Reforçando o contexto rico em ambigüidades que marcou as relações entre escravos e senhores, encontramos o costume de vestir as escravas com roupas semelhantes às das sinhás, por vezes complementando a indumentária com peças de ouro e prata. Esses privilégios eram mais comuns entre as escravas da casa, como nos mostra a ilustração de Debret (Casamento de negros pertencentes à família rica, 1828, aquarela, 15,7 x 21,6 cm, Museus Castro Maya, Rio de Janeiro), aquelas que usualmente acompanhavam em cortejo a família branca pelas ruas. Vilhena comenta sobre o luxo das mulheres de Salvador (VILHENA, 1921, P.47):

As peças com que se ornam são de excessivo valor e quando a função o permite aparecem com suas mulatas e pretas vestidas com ricas saias de cetim, becas de lemiste finíssimo, e camisas de cambraia, ou cassa, bordadas de forma tal que vale o lavor três ou quatro vezes mais que a peça e tanto é o ouro que cada um leva em fivelas, cordões, pulseiras, colares ou braceletes e bentinhos que sem hipérbole basta para comprar duas ou três negras ou mulatas como a que o leva.

A crueldade do sistema se explicita quando reconhecemos que mesmo que um negro escravo leve sobre si roupas e ouro suficientes para pagar pelo seu valor de compra, isso não implica na possibilidade de sua liberdade. Essa cultura de excessos visíveis era bastante generalizada entre os brancos de locais como Rio de Janeiro e Salvador. Nos diz Mattoso sobre a Bahia:

Fica claro, entretanto, que falam de uma opulência que é da Bahia inteira. Apenas os vagabundos e os mendigos estão excluídos dessa riqueza geral. Dela participa até mesmo a massa de escravos, sobre a qual respinga o esplendor do mestre... (MATTOSO, 1997, P.156).

No entanto, vale aqui apontar para um conjunto de medidas legais editadas no século XVIII, estudados por Lara (LARA, 2000,179), que traduzem a preocupação das autoridades da metrópole com o luxo exibido pelas escravas, evitando o perigo de confusão na percepção da hierarquia social. $\mathrm{Na}$ verdade as limitações impostas pelas cartas régias e pareceres do conselho ultramarino nos séculos XVI e XVII eram aplicáveis inicialmente a todos, sem menção específica às roupas dos escravos. A quantidade de escravos era um dos objetos das restrições que visavam regular a opulência exibicionista dos senhores.

A preocupação com os escravos é expressa na legislação de 1749 onde se proíbe o uso de certos tecidos e ornamentos sob pena de multa, açoitamento ou degredo para São Tomé. 
No século XVIII é freqüente a relação entre a questão da ostentação entre as escravas e as observações feitas sobre as mulheres que circulavam a noite pela cidade, com freqüentes referências a escravas, mas muitas vezes sem diferenciar as cativas e as libertas. Aqui a associação do luxo é feita de modo bastante direto à luxúria pecaminosa das "mulheres de tarifa". A ostentação é relacionada com a desonra das mulheres que circulam solitárias, sem o acompanhamento de suas senhoras.

Por ser informado dos grandes inconvenientes que resultam nas Conquistas da liberdade de trajarem os negros, e os mulatos, filhos de negro, ou mulato, ou de mãe negra, da mesma sorte que as pessoas brancas, proíbo aos sobreditos, ou sejam de um, ou de outro sexo, ainda que se achem forros, ou nascessem livres, o uso não só de toda sorte de seda, mas também de tecidos de lã finos, de holandas, esguiões, e semelhantes, ou mais finos tecidos de linho, ou de algodão; e muito menos lhes será lícito trazerem sobre si ornato de jóias, nem de ouro ou prata, por mínimo que seja (FREYRE, 2004, P. 529).

Havia aqui a intenção, que o tempo demonstrou infrutífera, de estabelecer a exclusividade do luxo aos indivíduos brancos. Apesar de se embasar em argumentos que apontavam para o risco de gerar dano a honestidade das famílias cristãs através do abuso da vaidade, as determinações foram anuladas após menos de quatro meses da promulgação, sem que possamos conhecer as exatas razões. A sociedade senhorial parece não ter se acomodado à situação de ver limitadas suas possibilidades de exibição de riqueza e poder. Fosse através da sofisticação do vestuário destinado ao convívio social, ou do acompanhamento de grupos de escravos ricamente paramentados a carregar as douradas cadeirinhas, as limitações legais não foram suficientes para modificar os hábitos ostentatórios vigentes.

Mas sabemos que a exibição de vestimentas e ornamentos era de uso de uma minoria de escravos. As peças mais comuns elencadas nos anúncios de escravos fugidos no Diário de Pernambuco nos dão uma idéia de seu vestuário. São mencionadas camisas, ceroulas de algodão, calças e camisas de estopa, camisas de algodão grosso e calças de canga. Para as mulheres aparecem os vestidos de pano da costa e de chita. Para a grande maioria a indumentária se construía dentro de limites impostos pelas condições precárias de vida, a negação de sua liberdade de escolha e por critérios de adequação social. Karasch lembra que na década de 1850 permanecia o costume que proibia aos escravos a utilização de sapatos.(KARASH, 2000, P.188) Portanto, é a partir da perspectiva da construção de costumes de matriz africana, mas adaptados às possibilidades locais que devemos analisar a indumentária do negro.

O vestuário das baianas é um dos conjuntos de indumentária afro-brasileira mais conhecidos. Nina Rodrigues aponta para os elementos que o compõe:

saias de cores vivas, de larga roda. O tronco coberto da camisa é envolvido no pano da Costa, espécie de comprido chalé quadrangular, de grosso tecido de algodão, importado da África. O pano da Costa passa a tiracolo, sobre uma espádua, por baixo do braço oposto, cruzadas na frente as extremidades livres (RODRIGUES, 1977, P. 118).

Outra peça importante é o "torso, triângulo de pano cuja base cinge a circunferência da cabeça, indo prender-se as três extremidades na parte posterior ou nuca".(Ibid, p.118) Este padrão de indumentária foi criado a partir da combinação de influências diversas. A figura 
típica da baiana soma elementos da cultura nigeriana (os panos vistosos, as saias rodadas, os xales da Costa, os braceletes, os argolões), muçulmana (a rodilha ou turbante) e angolacongolenses (miçangas e balangandãs) (RAMOS, 1979, p.198).

$\mathrm{Na}$ pintura "Baiana" a personagem apresenta adereços de marca afro-brasileira, com colares que criam uma identidade regional ligada à Bahia, mas com indumentária distante da tipologia tradicional de pano da costa e torso. O volume de adereços de ouro é sinal de opulência, mas o simples fato de se tratar de uma pintura individual, nos sugere que não se trata de exemplificar a riqueza de outrem, mas projeção de auto-imagem possivelmente a partir de iniciativa individual. Os adereços não adornam uma "peça", escrava, apontando para a posição de seu senhor uma vez que não há sinais de subordinação a ninguém. O conjunto de elementos indica uma apropriação, por parte da retratada, da ostentação como estratégia de diferenciação. Se por um lado incorpora os valores que a compostura da indumentária conservadora testemunham, por outro, sua apresentação em modelo ocidental não objetiva testemunhar sobre a ação civilizadora de senhores/proprietários sobre si.

Mas no retrato vemos, além das luvas, lenço nas mãos e brincos ocidentais, o impactante conjunto de joalheria afro-brasileira. Testemunho de outros modos, outros valores, pedem também a validação de outros olhares. Olhares que reconheçam sua qualidade estética, e que saibam ler a variedade de significados que trazem. São também negros os olhares que reconhecem plenamente nos colares, modos de distinção específicos de seu grupo de pertencimento. Além de designar etnicidade, tem também significados relacionados à gênero. Gilberto Freyre diferencia os "modos de homem", relacionados a "maneiras, feições ou formas particulares e, até, jeitos, artes e comedimentos próprios de homens bem educados”, das "modas de mulher" que seriam os "gostos e formas de vestir, calçar e pentear "responsáveis pela expressão da feminilidade" (FREYRE, 1997, P.42). No contexto da patriarcal sociedade brasileira a "mulher ornamental", na denominação do autor, deveria servir-se de artifícios requintados que pudessem destacar seus encantos femininos aos olhos dos homens, fossem eles seus pais ou maridos, sempre seus senhores Mas neste caso há especificidades quanto ao papel feminino pelo fato de se tratar de uma mulher negra. Como observa o próprio Freyre ao afirmar:

A identidade feminina do século XIX não se aplica de modo generalizado à mulher negra escrava em função de sua relação com o trabalho (Ibid).

Os colares de contas douradas que vemos no retrato da "Baiana" são exemplos da joalheria crioula usada por negros e negras na Bahia do século XIX (Colar (Grilhão), séculos XVIII - XIX, ouro, 117 x 1,7 cm, Coleção particular; Colar, séculos XVIII - XIX, ouro, 70 $\mathrm{cm}$, Coleção particular). A origem dessa joalheria provém dos cultos religiosos afro-brasilreiros. A técnica da fundição utilizada em sua confecção foi introduzida pelos negros malês africanos que dominavam as propriedades e o manuseio dos metais. O orixá relacionado ao trabalho com metal é Ogum. Este deus-ferreiro, artesão divino detentor do poder sobre todos os metais, é o orixá senhor da forja e do fogo. O dourado das contas, por sua vez, está relacionado a Oxum, deidade das águas doces e da riqueza.

$\mathrm{Na}$ joalheria dos candomblés, as contas metálicas como as dos colares dos retratos são indício de status dentro das famílias de santo. Estes fios-de-contas são herdados pelos descendentes na hierarquia dos terreiros tradicionais. Algumas peças da joalheria religiosa afro- 
brasileira saíram dos cultos e se proliferaram entre as negras e mulatas da província (Baianas com jóias, séc. XIX, Lindemann, Fotografia, Coleção Berbert de Castro, Salvador). Verger afirma sobre a difusão destes costumes:

As jóias usadas pelas mulheres africanas na Bahia são muito bonitas e de concepção muito original. Isto tanto para as que ainda são escravas a serviço das grandes famílias, preocupadas com a afirmação de sua opulência até mesmo na riqueza dos ornamentos usados pelos escravos de casa (LODY,2001, P.109).

Em seu estudo sobre a joalheria afro-brasileira, Lody faz referência as bolas confeitadas que compõe colares como os que vemos na pintura. As contas esféricas eram confeccionadas na Bahia ou na região do Douro em Portugal. Para o autor o trabalho artesanal que vemos na superfície das contas esféricas apresentam semelhanças com elementos da cultura Portuguesa, como o trabalho luso-muçulmano da filigrana, ou até mesmo com a decoração da doçaria tradicional daquele país. Estabelece ainda paralelos com a visualidade dos arabescos e da escrita islâmica (Ibid).

Os fios de conta metálicos vistos no retrato em estudo se assemelham aos utilizados, ainda hoje, pelas senhoras da irmandade da Boa Morte em Cachoeiro do Itapemirim na Bahia. Criada para contribuir para a libertação dos negros escravos, arrecadando dinheiro para alforrias e resguardando negros fugidos, a irmandade ainda mantém atividades de cunho festivo e também de caráter social-comunitário. As mulheres de irmandades como esta eram chamadas de negras de partido alto, denominação indicativa de diferenciação social. $\mathrm{O}$ dado mais relevante a apontar é o fato das irmandades serem testemunho do cruzamento cultural fundamental na história negra brasileira: aquele em que se encontram a religiosidade africana e a cristã. A origem de alguns dos principais terreiros da Bahia se entrelaça com a história da irmandade, apesar de sua forte ligação com a Igreja católica. Com seus cultos cheios de segredos, exemplificam uma luta de séculos em que a articulação social e a manutenção da memória cultural adquirem extrema importância.

Nos rituais sagrados nas igrejas ou em festividades do candomblé, essas mulheres desfilavam sua joalheria, seus panos da costa e seus amuletos, testemunhos de seus deslocamentos no espaço e no tempo. Mesmo sem termos condições de relacionar, a retratada, a uma irmandade específica, o mais importante é reconhecer o contexto que nos apresenta um conjunto de mulheres: com papel de liderança em sua comunidade, responsáveis pela manutenção de valores tradicionais de seu grupo de pertencimento, reconhecidas como um grupo diferenciado. Isso é especialmente válido para as mulheres da Irmandade da Boa Morte, mas é também verdadeiro para as mulheres negras livres de modo geral. O modo como esta distinção reconhecida e legitimada socialmente se tornava visível, pode nos informar sobre a natureza dos códigos e valores culturais. Neste caso se tratam de valores religiosos, afirmados pela relação com a joalheria e sua simbologia e, com a dupla via de espiritualidade das irmandades.

Este grupo de mulheres de aparência muito católica praticante, são ao mesmo tempo, as fiéis guardiãs dos cultos africanos dos orixás nago-oruba da atual Nigéria e do Daomé (Ibid, p. 221).

É natural pensar que para a mentalidade da hierarquizada sociedade brasileira do oitocentos, os conceitos de indivíduo negro e indivíduo escravo dificilmente se desvinculavam. 
Como conseqüência a percepção de indivíduos como portadores da marca da cor sobre a pele, estariam necessariamente ligados à idéia de inferioridade e disseminada ao longo de séculos. Os abolicionistas já levantavam estas questões e Joaquim Nabuco escreve em 1881 (Freyre, 2004, p. 399): "Em primeiro lugar o mau elemento da população não foi a raça negra, mas essa raça reduzida ao cativeiro". O abolicionista busca desconstruir a definição de negatividade atribuída aos africanos e seus descendentes. Este parece ser o discurso que a pintura "Baiana" busca fazer visualmente, mas sem adotar a perspectiva integracionista de branqueamento, ela mantém a marca da autenticidade africana/crioula. Esta operação é que parece inverter a polaridade dos discursos estabelecidos.

Transformar o gestual de um corpo herdeiro de gerações de trabalho escravo em uma linguagem corporal preocupada com os maneirismos da etiqueta oitocentista, certamente constituía um deslocamento considerável, e não há como supor como esta tarefa foi desempenhada por mulheres negras e em que medida. Souza comenta observações de Balzac sobre costumes, moda e hábitos de distinção social em que se aponta para o fato de que a hierarquia social não se evidencia exclusivamente através da exibição material, mas depende de demonstrações mais sutis que denotem a origem e sofisticação dos indivíduos. Escreve Souza: ...o nível social do indivíduo não é revelado pelas jóias, botões de ouro, correntes faustosas, rendas e opulência dos tecidos - e sim pela arte elaborada e difícil de "animar o repouso", tão ligada, por exemplo, a certos elementos secundários da toalete feminina, como o leque, a echarpe e o chale, cuja voga presenciou atravessando o século de ponta a ponta (SOUZA, 1987, P.135).

Na pintura "Baiana" observamos que as mãos da retratada estão cobertas por delicadas luvas brancas e seguram um lenço. Aqui objetos e gestos em potência se combinam para ajudar a compor a imagem de senhora respeitável e pronta para a situação de convívio em meio a um grupo social destacado. Não se trata apenas de combinar objetos como atributo de classe, mas também de anunciar possibilidades de comportamento que traduzam a adequação que se espera de um indivíduo em dada posição social.

As luvas femininas ajudam a criar a imagem de distância do trabalho e de educada delicadeza feminina. O lenço traz em si o anúncio de seu manuseio em leves movimentos da mão que se aproxima do rosto para chamar a atenção da beleza da mulher.

É que a medida em que as diferenças exteriores se atenuam pela generalização da moda, o indivíduo tende a revelar o seu nível não tanto pela fazenda, o chapéu, as jóias, mas pela educação, jeito de andar, maneiras (Ibid, p. 137).

É importante constatar que, se tradicionalmente a busca de afirmação social se expressa pela sobreposição de objetos e gestos relacionados à cultura branca, no retrato surge uma inversão. Os colares assumem a situação de destaque máximo como significantes, garantindo que o caráter de distinção social da personagem se desse em função de uma ótica que vai além dos valores hegemônicos vigentes. Nesta operação a retratada consegue se distanciar da associação inequívoca que relaciona negro e escravo e também aos códigos estabelecidos que historicamente sinalizem a inserção social. Compondo a visualidade de negro escravo temos, usualmente, a relação com o trabalho, as roupas de origem africana ou afro-brasileiro, os pés descalços, a presença dos senhores. As imagens de negros livres incorporavam os signos diferenciadores de propriedade de comportamento dos brancos. Mas aqui se quebra esse jogo 
de oposição. A afirmação de identidade autônoma da mulher se faz através de elementos de significação de origem negra.

A afirmação de negritude e portanto de distinção cultural e, em parte, a afirmação de distinção social correm paralelas e não dissociadas como usualmente ocorre. É claro que as roupas e jóias ocidentais complementam a construção da imagem, mas não carregam em si o potencial de comunicação de valores para os observadores negros do retrato. Aí se estabelece outro aspecto subversivo da obra, uma vez que desvirtua o circuito de circulação das pinturas deste gênero.

Além de exibir uma personagem não habitual desta categoria de imagem no oitocentos brasileiro, por fazer parte de um grupo social que não era visto como digno de perpetuar suas imagens por este meio, a pintura provavelmente foi criada para ser vista por outros negros. A hipótese de produção da pintura a partir da dinâmica de uma irmandade religiosa pode nos levar a imaginar que o local de exibição da pintura fosse um espaço em uma igreja freqüentado pela comunidade negra. Neste contexto os significados de classe, raça e religiosidade imbricados na obra seriam compreendidos e apreciados pelos pares da retratada.

Talvez um grupo negros, iguais em sua origem, tenha podido contemplar a pintura, reconhecendo na imagem um membro de um grupo cujos laços carregavam significados valiosos. A continuidade no tempo, prometida pelo gênero do retrato, se soma aqui a outros sentidos espirituais agregadores. A perenidade da imagem se relaciona, no olhar destes homens e mulheres, à permanência constituidora da ancestralidade. A imagem da mulher retratada materializa aos seus descendentes, parentes e afetos, sua existência passada, fazendo com que ela possa continuar no presente entre os seus, através do olhar dos seus. A imagem de um retrato deve revelar aos olhos a articulação entre a existência física de um indivíduo, e sua individualidade invisível, subjetiva e abstrata. Reconhecer esta dimensão abstrata dos sujeitos, que torna cada ser único resulta em uma concepção do corpo retratado como ponto de interseção da vida e do pensamento.

O século XIX abre poucas possibilidades para este "dar-se a ver" dos indivíduos negros, relegando à invisibilidade tudo que se desviasse do estrito escopo de representação dos padrões dominantes. O poder de produção das imagens, até o advento da fotografia está concentrado em número reduzido de indivíduos. E estes tinham pautas restritas ao definir a escolha de seus assuntos. Às mulheres negras cabia ilustrar a surpreendente variedade de tipos femininos de origem africana dentro de suas especificidades de trabalho, sensualidade e sexualidade.

A imagem nega as relações de percepção de diferenças presa a convenções estanques. Como nos diz Montes:

A diferença que se assinala pelo espaço e pelo gestual, nas atitudes opostas de negros e brancos: os que fazem e os que observam. Um corpo que se perde na paisagem, coisa entre coisas, e que aponta para um não lugar social, ou apenas para o lugar de um "tipo", em retratos de negros, que no estúdio fotográfico se congelam, fora de lugar, em suas lides cotidiana (MONTES, 2000, p.64).

O retrato a "Baiana" veste esta mulher negra. Não apenas com roupas de senhora, como já era hábito de escravas e libertas; não apenas com adereços crioulos ou africanos, já vistos em sua dimensão de exotismo em diversos contextos. O vestir neste caso é mais um revestir de dignidade que parece exalar das intenções de auto-representação da retratada. Sua 
pose e modo de apresentação buscam fixar sua imagem de acordo com padrões louváveis e legitimados por seu grupo de pertencimento. A identidade de nossa personagem se constrói na adoção destes modos e valores, na simultânea subversão que opera ao combiná-los a elementos que são os seus próprios, e que denotam sua origem africana. Assim como os colares, a pintura revel seus poders mágicos. Nas palavras de Alberti, a pintura possui "a força divina de fazer presentes os ausentes; mais ainda, de fazer dos mortos, depois de muitos séculos, seres quase vivos“.(ALBERTI, 1999, p.101). É assim, por mágica e com mágica que nos chega a figura da Baiana.

\section{Bibliografia}

ALBERTI, Leon Batista. Da Pintura. Campinas: Editora da Unicamp, 1999

CLARK, K. The Nude. Nova York: MJF Books, 1956.

COSTA, C. A imagem da mulher: um estudo de arte brasileira, São Paulo, Senac, 2002.

FREYRE, G., Casa Grande e Senzala: formação da família rasileira sob o regime da economia patriarcal. São Paulo: Global, 2004.

FREYRE, G. Modos de homem e modas de mulher. Rio de Janeiro: Record, 1997.

KARASCH, M. A vida dos escravos no Rio de Janeiro 1808-1850. São Paulo. Companhia das Letras. 2000.

LODY, R., Jóias de Axé: fios-de-conta e outros adornos do corpo: a joalheria afro-brasileira. Rio de Janeiro: Bertrand Brasil, 2001.

MATTOSO, K. M. de Queiroz. A Opulência na província da Bahia. In: Novais, Fernando (Org.). Historia da vida privada no Brasil: Império. São Paulo: Companhia das Letras, 1997.

MICELI, Sergio. Imagens negociadas: retratos da elite brasileira. São Paulo: Schwarcz, 1996.

MONTES, Maria Lúcia. Olhar o corpo. In: NEGRO de Corpo e Alma. Mostra do Redescobrimento. São Paulo, Associação Brasil 500 Anos, 2000.

RODRIGUES, N. Os africanos no Brasil. São Paulo: Nacional, 1977.

PARKES; Pollock. Old Mistresses. In: FRANSCINA, Francis et al. Modernidade e Modernismo: a pintura francesa no século XIX. São Paulo: Cosac \& Naify, 1998.

PESSANHA, José Américo. Despir os nus. In: O DESEJO na Academia. São Paulo, Pinacoteca do Estado, 1992. Catálogo.

RAMOS A. As culturas negras no novo mundo, São Paulo, Brasiliana, 1979

S. H. LARA. Sedas, Panos e Balangandãs: o traje de senhoras e escravas nas cidades do Rio de Janeiro e Salvador (século XVIII). In: Maria Beatriz N. da Silva (org) - Brasil: Colonização e Escravidão. Rio de Janeiro, Nova Fronteira, 2000, pp. 177-191.

SOUZA, G. de Mello e. O espírito das Roupas: a moda no século XIX. São Paulo: Companhia das Letras, 1987.

VILHENA, L. S. Recopilação de notícias soteropolitanas e brasílicas contidas em XX cartas (1802). Salvador: Imprensa Oficial do Estado, 1921. 